\title{
The Efficacy of Ultrasonography in Prediction of the Degree of Placental Accretion among Cases of Placenta Previa
}

\author{
Esmail Mohamed Talaat El Garhy, Abd El Fatah Mohamed El Senity, Ahmed Gaber Ahmed Rizk* \\ Department of Obstetrics and Gynecology, Faculty of Medicine, Al-Azhar University, Cairo, Egypt \\ * Corresponding author: Ahmed Gaber Ahmed Rizk, Mobile: (+20) 1285663854, email: prosso_2000@yahoo.com
}

\begin{abstract} been used widely for antenatal screening and diagnosis of AIP. assess the impact of prenatal diagnosis in our population. examinations. hysterectomy.

\section{INTRODUCTION}

Abnormally invasive placentas are a lifethreatening condition characterized by placental villi being abnormally adherent to the myometrium as a result of the absence of, or defects in, the normal decidual basalis and the fibrinous Nitabuch's layer (1).

They are commonly classified into three distinct grades according to the degree of the placental villi invasion into the myometrium: placenta accreta (placental villi are attached to the decidual surface of the myometrium), placenta increta (placental villi more deeply invading into the myometrium) and placenta percreta (placental villi invade through the myometrium and the uterine serosa and sometimes into adjacent organs, such as the bladder. However, in a clinical setting and daily practice, these histopathological differences are probably nonexistent. Therefore, the term "placenta accreta" is used as a general term to describe all of these three conditions whereas the term percreta refers to placenta percreta ${ }^{(2)}$.

The incidence of placenta accreta has increased and seems to parallel the increasing cesarean delivery rate. Researchers have reported the incidence of placenta accreta as 1 in 533 pregnancies for the period of 1982-2002. This contrasts sharply with previous reports, which ranged from 1 in 4,027 pregnancies in the 1970s, increasing to 1 in 2,510 pregnancies in the $1980 \mathrm{~s}{ }^{(3)}$.
\end{abstract}

Background: Placenta previa and previous cesarean section are the two most important known risk factors for abnormally invasive placenta (AIP). AIP can be predicted as early as in the first trimester, and almost always confirmed in the second and third trimesters via Grayscale ultrasonography, with or without color Doppler has

Objectives: To evaluate the accuracy of ultrasound in the diagnosis of placenta accreta and its variants, and to

Patients and Methods: A total of 60 women with placenta previa were enrolled prospectively. All those patients presented during the period of December 2017 till December 2018 to Ghamra Military and Sayed Galal Obstetrics outpatient clinic during their follow up visits in the 2nd and 3rd trimesters and underwent ultrasound

Results: A number of ultrasound criteria can be used for in diagnosis of placenta accreta, as this study showing their high accuracy, they include loss of retroplacental clear zone, presence of abnormal placental lacunae, myometrial thinning, bladder wall interruption and uterovesical hypervascularity. On the other hand, both loss of retroplacental clear zone and abnormal placental lacunae could predict which patient will mostly have CS

Conclusion: It could be concluded that gray scale and color Doppler ultrasound have good performance in the diagnosis of AIP and that prenatal diagnosis improves maternal outcome.

Keywords: Cesarean section - Co-morbidities - Efficacy- Operative findings - Placenta accreta - Ultrasound.

Women at greatest risk of placenta accreta are those who have myometrial damage caused by a previous cesarean delivery with either anterior or posterior placenta previa overlying the uterine scar. Many literature reviews have shown that in the presence of a placenta previa, the risk of placenta accreta was $3 \%, 11 \%, 40 \%, 61 \%$, and $67 \%$ for the first, second, third, fourth, and fifth or greater repeat cesarean deliveries, respectively ${ }^{(4)}$.

Transvaginal and transabdominal ultrasonography are complementary diagnostic techniques and should be used as needed. Transvaginal ultrasound is safe for patients with placenta previa and allows a more complete examination of the lower uterine segment. Sonographic findings that have been associated with placenta accrete: (1) Loss of normal hypoechoic retroplacental zone ; (2) Multiple vascular lacunae (irregular vascular spaces) within placenta, giving "Swiss cheese" appearance; (3) Blood vessels or placental tissue bridging uterine-placental margin, myometrial-bladder interface, or crossing uterine serosa1; (4) Retroplacental myometrial thickness of $1 \mathrm{~mm}$ and/or (5) Numerous coherent vessels visualized with 3-dimensional power Doppler in basal view ${ }^{(5)}$.

Overall, grayscale ultrasonography is sufficient to diagnose placenta accreta, with a sensitivity of $77-87 \%$, specificity of $96-98 \%$, a positive predictive value of $65-93 \%$, and a negative 
predictive value of 98. The use of power Doppler, color Doppler, or three-dimensional imaging does not significantly improve the diagnostic sensitivity compared with that achieved by grayscale ultrasonography alone.

The aim of the study was to assess the efficacy of ultrasound (2D gray scale and Doppler study) via trans-abdominal and/or trans-vaginal approach in the prediction of the operative findings and possible associated co- morbidities, thus to optimize and individualize preoperative preparations and set the operative plan among placenta accreta cases, thus improving the post-operative outcomes.

\section{PATIENTS AND METHODS}

This prospective study included a total of 60 pregnant women diagnosed as placenta previa by ultrasonography, attending at Ghamra Military Hospital and Sayed Galal Obstetrics outpatient clinic, Al-Azhar University Hospitals. This study was conducted between December 2017 till December 2018. Patients were candidates for repeated elective CS or elective hysterectomy (if the diagnosis of placenta accreta is confirmed). They were presented during their follow up visits in the $3^{\text {rd }}$ trimester.

Ethical approval and written informed consent: Approval of the Al-Azhar University Academic and Ethical Committee was obtained. Written informed consent from all the subjects were obtained for acceptance of the operation.

\section{Inclusion criteria:}

- Maternal age from 20 to 40 years.

- Gestational age >28 weeks, confirmed by the first day of the last menstrual period or first trimesteric ultrasound.

- Single living fetus.

- One or more cesarean section.

- Placenta previa (all grades) with high possibility of morbidly adherent placenta accreta (all types).

\section{Exclusion criteria:}

- Maternal chronic medical disorder (diabetes mellitus or hypertension).

- Pregnancy induced disorders (preeclampsia or gestational diabetes).

- Associated fetal anomalies.

- Emergency or unplanned cesarean for cesarean hysterectomy.

\section{All patients were subjected to: \\ 1-Personal History}

Name, age, residence, occupation, marital status and special habits of medical importance particularly smoking, alcohol intake and drug abuse.

\section{2-Obstetric History:}

- Obstetric code and mode of delivery.

- Gestational age by date and first trimester ultrasound.

- Past obstetric history including recurrent miscarriage, preterm delivery, pre.eclampsia , unexplained stillbirth .

\section{3-Past History:}

- History of medical diseases particularly diabetes mellitus, hypertension, coronary heart disease, liver and kidney.

- History of previous operations or accidents.

- History of previous blood transfusions.

- History of drug intake.

\section{4- Full clinical examination:}

General examination :

Including vital signs, chest, cardiac, lower limbs, upper limbs and breast examination.

\section{Abdominal examination :}

- Inspection: looking for fetal movements, scars of previous Operations, any stria gravidarum or linea nigra and to assess the shape of the uterus and note any asymmetry.

- Palpation: assessment of fundal level, fetal lie , presentation .

- Auscultation: fetal heart auscultation .

\section{5- Investigations:}

All patients were subjected to routine preoperative laboratory investigations including CBC, Coagulation profile, urea, creatinine, ALT, AST and random plasma glucose to exclude uncontrolled medical conditions.

Ultrasound examination (2D gray scale and color doppler) via transabdominal and/or transvaginal approach using an ultrasound machine (Voluson Pro-V and GE Voluson E10):

a. Routine obstetric ultrasound including confirmation of the gestational age.

b. Confirming the presence of placenta previa (presence of placental tissue covering the internal os) or low-lying placenta (presence of placental tissue within $2 \mathrm{~cm}$ from the internal os and does not cover it).

c. To assess the possibility of concomitant placenta accreta (Sonographic findings that have been associated with placenta accreta (1) Loss of normal hypoechoic retroplacental zone (2) Multiple vascular lacunae (irregular vascular spaces) within placenta, giving "Swiss cheese" appearance (3) Blood vessels or placental tissue bridging uterine-placental margin, myometrialbladder interface, or crossing uterine serosa1 (4) Retroplacental myometrial thickness of $1 \mathrm{~mm}$ (5) Bladder wall interruption (6) Presence of placental 
bulge (7) Utero-vesical hypervascularity presence of lacunae feeder vessels.

d. Assessment of the adjacent structures that may be invaded by placenta percreta.

N.B. Ultrasound was performed by two expert sonographers.

6. Termination of pregnancy by elective cesarean section and/or cesarean hysterectomy.

7. Documentation of the operative findings during cesarean section and/or cesarean hysterectomy procedures.

8. Histopathological examination of the hysterectomy specimens to assess the degree of myometrial invasion.

\section{Statistical analysis}

Recorded data were analyzed using the statistical package for social sciences, version 20.0 (SPSS Inc., Chicago, Illinois, USA). Quantitative data were expressed as mean \pm standard deviation (SD). Qualitative data were expressed as frequency and percentage.

\section{The following tests were done:}

- Independent-samples t-test of significance was used when comparing between two means.

- Chi-square $\left(\mathrm{x}^{2}\right)$ test of significance was used in order to compare proportions between two qualitative parameters.

- The confidence interval was set to $95 \%$ and the margin of error accepted was set to 5\%. The pvalue was considered significant as the following:
- P-value $<0.05$ was considered significant.

- P-value <0.001 was considered as highly significant.

- P-value >0.05 was considered insignificant.

\section{RESULTS}

This study is a prospective study at Ghamra Military and Sayed Galal hospital during time interval from December 2017 till December 2018. The included 60 pregnant women who presented with diagnosis of placenta previa and had met the inclusion criteria were further subdivided into two groups:

Accreta $\operatorname{group}(\mathbf{n}=35)$ : included patients with placenta previa with invasion.

Not accreta group $(\mathbf{n}=25)$ : included patients with placenta previa without invasion.

Of 60 women in the final analysis, $35(58.3 \% \%)$ women had histological confirmation of morbidly adherent placenta, and the remaining 25 (41.7\%) women served as the control group.

As regard accreta group, Out of 35 cases of placenta previa with abnormal invasion, 16 cases $(45.7 \%)$ were histopathologically confirmed as placenta accreta and 19 cases $(54.3 \%$ ) were confirmed as placenta increta.

Cesarean hysterectomy was performed for all accreta group patients 35 patients $(100 \%)$ and was performed for 7 patients $(28 \%)$ in the not accreta group.

- Probability (P-value)

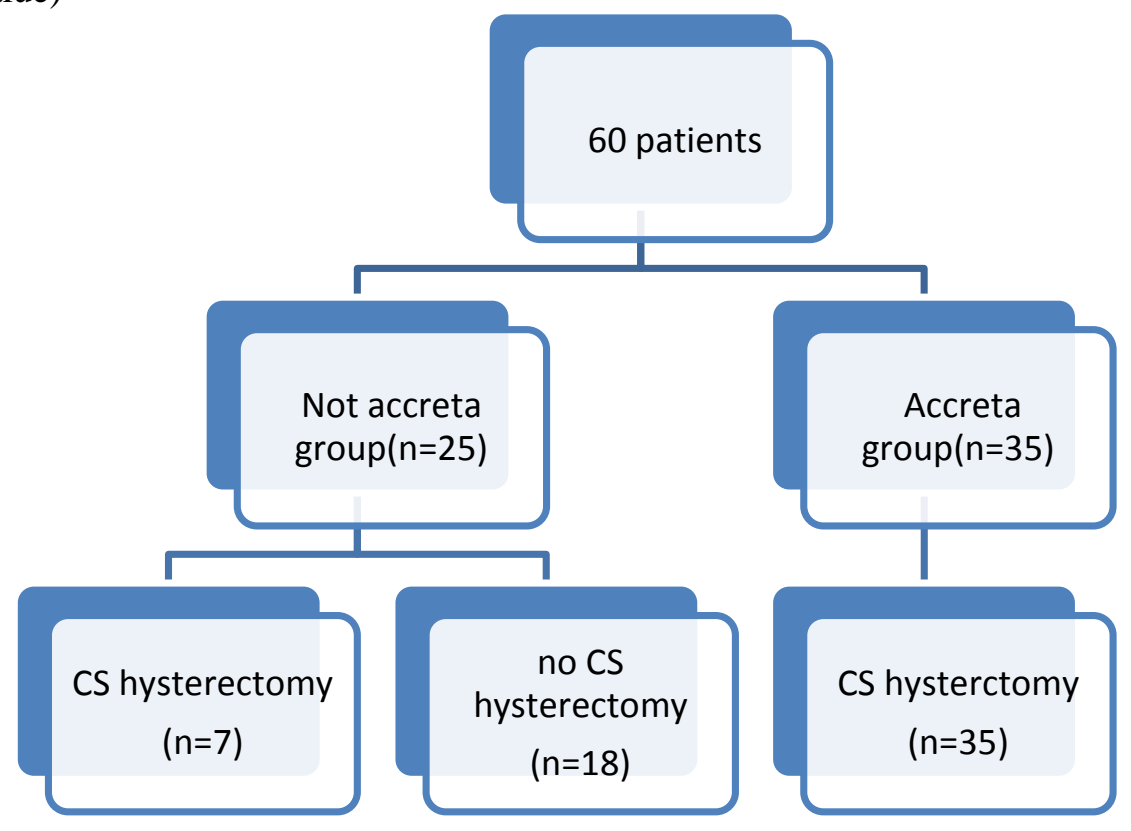

Figure (1) Flow chart showing the distribution of the patients included in the study. 
Table (1): comparison between cases of placenta accreta group and not accreta group regarding age, parity, gestational age, number of previous CS and estimated blood loss .

\begin{tabular}{|c|c|c|c|c|c|}
\hline & \multicolumn{4}{|c|}{ Histopathology } & \multirow[b]{3}{*}{ P value } \\
\hline & \multicolumn{2}{|c|}{ Accreta $(n=35)$} & \multicolumn{2}{|c|}{ Not $\operatorname{accreta}(n=25)$} & \\
\hline & Mean & $\begin{array}{l}\text { Standard } \\
\text { Deviation }\end{array}$ & Mean & $\begin{array}{l}\text { Standard } \\
\text { Deviation }\end{array}$ & \\
\hline Age (years) & 31.20 & 4.89 & 32.44 & 5.22 & 0.350 \\
\hline GA (weeks) & 35.83 & 2.33 & 35.92 & 2.27 & 0.880 \\
\hline Estimated blood loss (ml) & 2642.86 & 824.37 & 2056.00 & 1065.79 & 0.019 \\
\hline NO. of CS & 2.60 & 1.01 & 2.92 & 1.15 & 0.258 \\
\hline Parity & 2.91 & 1.07 & 3.32 & 1.18 & 0.170 \\
\hline
\end{tabular}

There were no statistically significant differences regarding age, parity, number of CS or gestational age at ultrasound between both groups. On the other hand, the estimated blood loss was significantly higher in the study group compared to the control group $(\mathbf{P}$ - value $\mathbf{= 0 . 0 1 9})$

Table (2): Correlation between the Loss of clear zone by ultrasound and histopathological Pattern

\begin{tabular}{|c|c|c|c|c|c|}
\hline & \multicolumn{2}{|c|}{ Histopathological Pattern } & \multirow[b]{2}{*}{ Total } \\
\hline & & & $\begin{array}{l}\text { Accreta } \\
(\mathrm{n}=35)\end{array}$ & $\begin{array}{l}\text { Not } \\
\operatorname{accreta}(n=7)\end{array}$ & \\
\hline \multirow{6}{*}{$\begin{array}{l}\text { Loss of } \\
\text { clear } \\
\text { zone }\end{array}$} & \multirow[t]{3}{*}{ Accreta } & Count & 29 & 1 & 30 \\
\hline & & $\%$ within Loss of clear zone & $96.7 \%$ & $3.3 \%$ & $100.0 \%$ \\
\hline & & $\begin{array}{l}\text { \% within Histopathological } \\
\text { Pattern }\end{array}$ & $82.9 \%$ & $14.3 \%$ & $71.4 \%$ \\
\hline & \multirow{3}{*}{\begin{tabular}{|l|} 
Not \\
accreta
\end{tabular}} & Count & 6 & 6 & 12 \\
\hline & & $\%$ within Loss of clear zone & $50.0 \%$ & $50.0 \%$ & $100.0 \%$ \\
\hline & & $\begin{array}{l}\text { \% within Histopathological } \\
\text { Pattern }\end{array}$ & $17.1 \%$ & $85.7 \%$ & $28.6 \%$ \\
\hline \multirow{3}{*}{\multicolumn{2}{|c|}{ Total }} & \multirow{3}{*}{$\begin{array}{l}\text { Count } \\
\% \text { within Loss of clear zone } \\
\% \text { within Histopathological } \\
\text { Pattern }\end{array}$} & 35 & 7 & 42 \\
\hline & & & $83.3 \%$ & $16.7 \%$ & $100.0 \%$ \\
\hline & & & $100.0 \%$ & $100.0 \%$ & $100.0 \%$ \\
\hline
\end{tabular}

Results showed highly statistically significant correlation between loss of clear zone and histopathological confirmation (P-value $<\mathbf{0 . 0 0 1})$.In addition, the overall Sensitivity, specificity, PPV ,NPV and accuracy were $82.9 \%, 85.7 \%, 96.7 \%, 50 \%$ and $83.3 \%$ respectively.

Table (3): Correlation between the presence of abnormal lacunae by ultrasound and histopathological Pattern

\begin{tabular}{|c|c|c|c|c|c|}
\hline & & & \multicolumn{2}{|c|}{ Histopathological Pattern } & \multirow[b]{2}{*}{ Total } \\
\hline & & & $\operatorname{Accreta}(n=35)$ & Not accreta $(\mathrm{n}=7)$ & \\
\hline \multirow{6}{*}{$\begin{array}{l}\text { Abnorma } \\
\text { l lacunae }\end{array}$} & \multirow[t]{3}{*}{ Accreta } & Count & 32 & 0 & 32 \\
\hline & & $\%$ within Abnormal lacunae & $100.0 \%$ & $0.0 \%$ & $100.0 \%$ \\
\hline & & $\%$ within Histopathological Pattern & $91.4 \%$ & $0.0 \%$ & $76.2 \%$ \\
\hline & \multirow{3}{*}{$\begin{array}{l}\text { Not } \\
\text { accreta }\end{array}$} & Count & 3 & 7 & 10 \\
\hline & & $\%$ within Abnormal lacunae & $30.0 \%$ & $70.0 \%$ & $100.0 \%$ \\
\hline & & $\%$ within Histopathological Pattern & $8.6 \%$ & $100.0 \%$ & $23.8 \%$ \\
\hline \multirow{3}{*}{\multicolumn{2}{|c|}{ Total }} & \multirow{3}{*}{$\begin{array}{l}\text { Count } \\
\% \text { within Abnormal lacunae } \\
\% \text { within Histopathological Pattern }\end{array}$} & 35 & 7 & 42 \\
\hline & & & $83.3 \%$ & $16.7 \%$ & $100.0 \%$ \\
\hline & & & $100.0 \%$ & $100.0 \%$ & $100.0 \%$ \\
\hline
\end{tabular}

Results showed highly statistically significant correlation between the presence of abnormal lacunae and histopathological confirmation (P-value $<\mathbf{0 . 0 0 1}$ ) .In addition, the overall Sensitivity, specificity , PPV ,NPV and accuracy were $91.4 \%, 100 \%, 100 \%, 70 \%$ and $92.9 \%$ respectively. 
Table (4): Correlation between the presence of bladder wall interruption by ultrasound and histopathological Pattern

\begin{tabular}{|c|c|c|c|c|c|}
\hline & & & \multicolumn{2}{|c|}{ Histopathological Pattern } & \multirow[b]{2}{*}{ Total } \\
\hline & & & $\operatorname{Accreta}(n=35$ & $\begin{array}{l}\text { Not } \\
\operatorname{accreta}(n=7)\end{array}$ & \\
\hline \multirow{6}{*}{$\begin{array}{l}\text { Bladder wall } \\
\text { interruption }\end{array}$} & \multirow[t]{3}{*}{ Accreta } & Count & 28 & 4 & 32 \\
\hline & & \begin{tabular}{|l|}
$\%$ within Bladder wall \\
interruption
\end{tabular} & $87.5 \%$ & $12.5 \%$ & $100.0 \%$ \\
\hline & & $\begin{array}{l}\text { \% within Histopathological } \\
\text { Pattern }\end{array}$ & $80.0 \%$ & $57.1 \%$ & $76.2 \%$ \\
\hline & \multirow{3}{*}{$\begin{array}{l}\text { Not } \\
\text { accreta }\end{array}$} & Count & 7 & 3 & 10 \\
\hline & & $\begin{array}{l}\text { \% within Bladder wall } \\
\text { interruption } \\
\end{array}$ & $70.0 \%$ & $30.0 \%$ & $100.0 \%$ \\
\hline & & $\begin{array}{l}\% \text { within Histopathological } \\
\text { Pattern }\end{array}$ & $20.0 \%$ & $42.9 \%$ & $23.8 \%$ \\
\hline \multirow{3}{*}{\multicolumn{2}{|c|}{ Total }} & \multirow{3}{*}{$\begin{array}{l}\text { Count } \\
\% \text { within Bladder wall } \\
\text { interruption } \\
\% \text { within Histopathological } \\
\text { Pattern }\end{array}$} & 35 & 7 & 42 \\
\hline & & & $83.3 \%$ & $16.7 \%$ & $100.0 \%$ \\
\hline & & & $100.0 \%$ & $100.0 \%$ & $100.0 \%$ \\
\hline
\end{tabular}

Results showed no statistically significant correlation between the presence of bladder wall interruption and histopathological confirmation (P-value $=\mathbf{0 . 1 9 5}$ ) .In addition, the overall Sensitivity, specificity, PPV ,NPV and accuracy were $80 \%, 42.9 \%, 87.5 \%, 30 \%$ and $73.8 \%$ respectively.

Table (5): Correlation between the Loss of clear zone by ultrasound and Intra-operative assessment

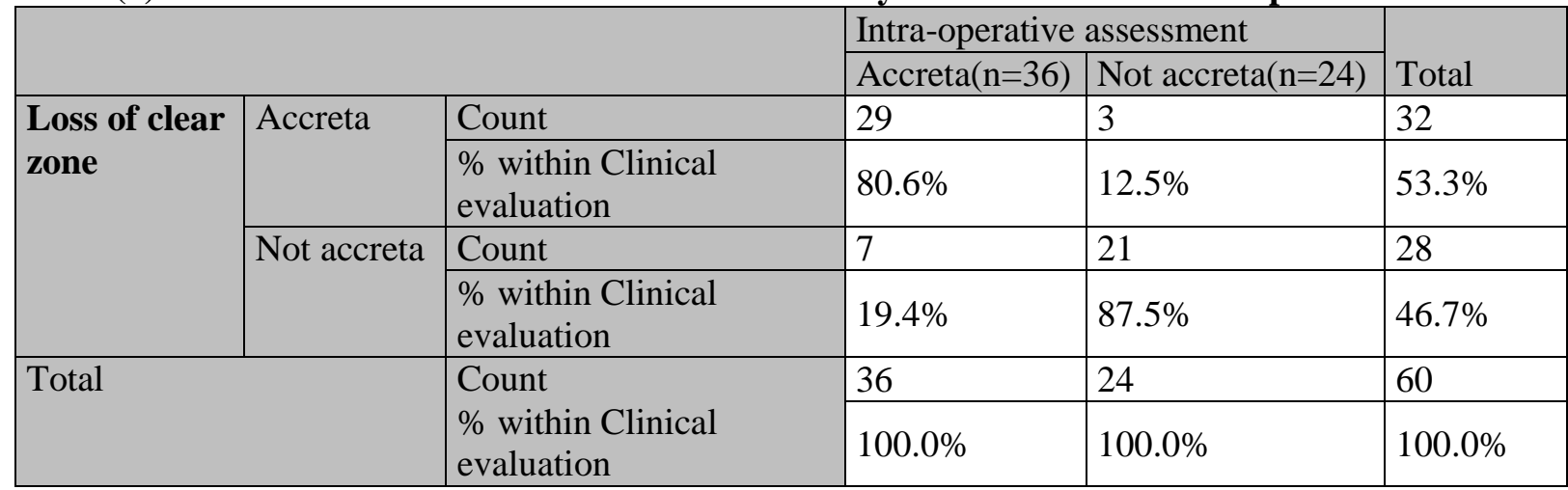

Results showed highly statistically significant correlation between loss of clear zone and Intra-operative assessment (P-value $<\mathbf{0 . 0 0 1}$ ) .In addition, the overall Sensitivity, specificity, PPV ,NPV and accuracy were $80.6 \%, 87.5 \%, 90.6 \%, 78.6 \%$ and $85 \%$ respectively.

Table (6): Correlation between the presence of abnormal lacunae by ultrasound and Intra-operative assessment

\begin{tabular}{|c|c|c|c|c|c|}
\hline & & & \begin{tabular}{|l} 
Intra-operative \\
\end{tabular} & assessment & \\
\hline & & & $\operatorname{Accreta}(n=36)$ & Not accreta $(n=24)$ & Total \\
\hline Abnormal & Accreta & Count & 31 & 3 & 34 \\
\hline & & $\begin{array}{l}\% \text { within Clinical } \\
\text { evaluation }\end{array}$ & $86.1 \%$ & $12.5 \%$ & $56.7 \%$ \\
\hline & & Count & 5 & 21 & 26 \\
\hline & accreta & $\begin{array}{l}\% \text { within Clinical } \\
\text { evaluation }\end{array}$ & $13.9 \%$ & $87.5 \%$ & $43.3 \%$ \\
\hline Total & & Count & 36 & 24 & 60 \\
\hline & & $\begin{array}{l}\% \text { within Clinical } \\
\text { evaluation }\end{array}$ & $100.0 \%$ & $100.0 \%$ & $100.0 \%$ \\
\hline
\end{tabular}

Results showed highly statistically significant correlation between loss of clear zone and Intra-operative assessment (P-value $<\mathbf{0 . 0 0 1})$.In addition, the overall Sensitivity, specificity, PPV ,NPV and accuracy were $86.1 \%, 87.5 \%, 94.1 \%, 88.4 \%$ and $91.7 \%$ respectively. 
Table (7): Correlation between the presence of placental bulge by ultrasound and Intra-operative assessment

\begin{tabular}{|c|c|c|c|c|c|}
\hline & \multicolumn{2}{|c|}{ Intra-operative assessment } & \multirow{3}{*}{$\begin{array}{l}\text { Total } \\
30\end{array}$} \\
\hline & & & $\operatorname{Accreta}(n=36)$ & Not $\operatorname{accreta}(n=24)$ & \\
\hline \multirow{4}{*}{$\begin{array}{l}\text { Placental } \\
\text { Bulge }\end{array}$} & \multirow[t]{2}{*}{ Accreta } & Count & 21 & 9 & \\
\hline & & $\begin{array}{l}\% \text { within Clinical } \\
\text { evaluation }\end{array}$ & $58.3 \%$ & $37.5 \%$ & $50.0 \%$ \\
\hline & \multirow{2}{*}{$\begin{array}{l}\text { Not } \\
\text { accreta }\end{array}$} & Count & 15 & 15 & 30 \\
\hline & & $\begin{array}{l}\% \text { within Clinical } \\
\text { evaluation }\end{array}$ & $41.7 \%$ & $62.5 \%$ & $50.0 \%$ \\
\hline \multirow{2}{*}{\multicolumn{2}{|c|}{ Total }} & \multirow{2}{*}{$\begin{array}{l}\text { Count } \\
\% \text { within Clinical } \\
\text { evaluation }\end{array}$} & 36 & 24 & 60 \\
\hline & & & $100.0 \%$ & $100.0 \%$ & $100.0 \%$ \\
\hline
\end{tabular}

Results showed no statistically significant correlation between the presence of placental bulge and intraoperative assessment (P-value $\mathbf{= 0 . 1 9 0})$.In addition, the overall Sensitivity , specificity , PPV ,NPV and accuracy were $58.3 \%, 62.5 \%, 66.7 \%, 50 \%$ and $58.3 \%$ respectively.

Table (8): Correlation between the presence of uterovesical hypervascularity by ultrasound and Intraoperative assessment

\begin{tabular}{|c|c|c|c|c|c|}
\hline \multicolumn{5}{|c|}{ Intra-operative assessment } & \multirow[b]{2}{*}{ Total } \\
\hline & & & $\operatorname{Accreta}(n=36)$ & Not $\operatorname{accreta}(n=24)$ & \\
\hline \multirow{4}{*}{$\begin{array}{l}\text { Uterovesical } \\
\text { hypervascularity }\end{array}$} & \multirow[t]{2}{*}{ Accreta } & Count & 29 & 5 & 34 \\
\hline & & $\begin{array}{l}\% \text { within Clinical } \\
\text { evaluation }\end{array}$ & $80.6 \%$ & $20.8 \%$ & $56.7 \%$ \\
\hline & \multirow{2}{*}{$\begin{array}{l}\text { Not } \\
\text { accreta }\end{array}$} & Count & 7 & 19 & 26 \\
\hline & & $\begin{array}{l}\% \text { within Clinical } \\
\text { evaluation }\end{array}$ & $19.4 \%$ & $79.2 \%$ & $43.3 \%$ \\
\hline \multirow{2}{*}{\multicolumn{2}{|c|}{ Total }} & \multirow{2}{*}{$\begin{array}{l}\text { Count } \\
\% \text { within Clinical } \\
\text { evaluation }\end{array}$} & 36 & 24 & 60 \\
\hline & & & $100.0 \%$ & $100.0 \%$ & $100.0 \%$ \\
\hline
\end{tabular}

Results showed statistically significant correlation between the presence of uterovesical hypervascularity and intra-operative assessment (P-value $<\mathbf{0 . 0 0 1}$ ) .In addition, the overall Sensitivity, specificity , PPV ,NPV and accuracy were $80.6 \%, 79.2 \%, 82.3 \%, 30 \%$ and $73 \%$ respectively.

Table (9): Correlation between the presence of bridging vessels by ultrasound and Intra-operative assessment

\begin{tabular}{|c|c|c|c|c|c|}
\hline & & & \multicolumn{2}{|c|}{ Intra-operative assessment } & \multirow[b]{2}{*}{ Total } \\
\hline & & & $\operatorname{Accreta}(n=36)$ & Not $\operatorname{accreta}(n=24)$ & \\
\hline \multirow{4}{*}{$\begin{array}{l}\text { Bridging } \\
\text { vessels }\end{array}$} & \multirow[t]{2}{*}{ Accreta } & Count & 21 & 10 & 31 \\
\hline & & $\begin{array}{l}\% \text { within Clinical } \\
\text { evaluation }\end{array}$ & $58.3 \%$ & $41.7 \%$ & $51.7 \%$ \\
\hline & \multirow{2}{*}{$\begin{array}{l}\text { Not } \\
\text { accreta }\end{array}$} & Count & 15 & 14 & 29 \\
\hline & & $\begin{array}{l}\% \text { within Clinical } \\
\text { evaluation }\end{array}$ & $41.7 \%$ & $58.3 \%$ & $48.3 \%$ \\
\hline \multirow{2}{*}{\multicolumn{2}{|c|}{ Total }} & \multirow{2}{*}{\begin{tabular}{|l|} 
Count \\
$\%$ within Clinical \\
evaluation
\end{tabular}} & 36 & 24 & 60 \\
\hline & & & $100.0 \%$ & $100.0 \%$ & $100.0 \%$ \\
\hline
\end{tabular}

Results showed no statistically significant correlation between the presence of bridging vessels and intraoperative assessment (P-value $\mathbf{= 0 . 3 1 5})$.In addition, the overall Sensitivity, specificity , PPV ,NPV and accuracy were $58.3 \%, 58.3 \%, 64.5 \%, 48.2 \%$ and $56.7 \%$ respectively. 
Table (10): Correlation between the presence of placental lacunae feeder vessels by ultrasound and Intra-operative assessment

\begin{tabular}{|c|c|c|c|c|c|}
\hline & & & \multicolumn{2}{|c|}{ Intra-operative assesment } & \multirow[b]{2}{*}{ Total } \\
\hline & & & $\operatorname{Accreta}(n=36)$ & Not accreta(n=24) & \\
\hline \multirow{4}{*}{$\begin{array}{l}\text { Placental } \\
\text { lacunea } \\
\text { feeder vessels }\end{array}$} & \multirow[t]{2}{*}{ Accreta } & Count & 19 & 11 & 30 \\
\hline & & $\begin{array}{l}\% \text { within Clinical } \\
\text { evaluation }\end{array}$ & $52.8 \%$ & $45.8 \%$ & $50.0 \%$ \\
\hline & \multirow{2}{*}{\begin{tabular}{|l|} 
Not \\
accreta
\end{tabular}} & Count & 17 & 13 & 30 \\
\hline & & $\begin{array}{l}\% \text { within Clinical } \\
\text { evaluation }\end{array}$ & $47.2 \%$ & $54.2 \%$ & $50.0 \%$ \\
\hline \multirow{2}{*}{\multicolumn{2}{|c|}{ Total }} & \multirow{2}{*}{$\begin{array}{l}\text { Count } \\
\% \text { within Clinical } \\
\text { evaluation }\end{array}$} & 36 & 24 & 60 \\
\hline & & & $100.0 \%$ & $100.0 \%$ & $100.0 \%$ \\
\hline
\end{tabular}

Results showed no statistically significant correlation between the presence of placental lacunae feeder vessels and intra-operative assessment $(\mathbf{P}$-value $\mathbf{= 0 . 7 9 3})$. In addition, the overall Sensitivity, specificity , PPV ,NPV and accuracy were $52.8 \%, 54.2 \%, 60 \%, 43.3 \%$ and $51.7 \%$ respectively.

\section{DISCUSSION}

This study was aimed to evaluate the sensitivity and specificity of each ultrasound criterion comparing them with the final outcome of pregnancy and assessment of placental invasion in cases of placenta previa anterior wall with previous uterine scar.

\section{Regarding the presence of abnormal placental} lacunae :

This study showed Sensitivity, specificity, PPV, NPV and accuracy were $91.4 \%, 100 \%, 100 \%, 70 \%$ and $92.9 \%$ respectively in correlation with histopathological assessment, in addition our study showed Sensitivity, specificity, PPV, NPV and accuracy were $86.1 \%, 87.5 \%, 94.1 \%, 88.4 \%$ and $91.7 \%$ respectively in correlation with intraoperative assessment.

The current study agreed with Comstock (6), who found that the presence of abnormal lacunae showed sensitivity $93 \%$ and PPV $93 \%$ in women at 20 weeks of gestation and beyond, whereas Calì et al. ${ }^{(7)}$ found that the presence of abnormal lacunae showed Sensitivity $73.0 \%$, specificity $86.7 \%$, and Yang $\boldsymbol{e t}$ al. ${ }^{(8)}$ who found that the presence of abnormal lacunae showed sensitivity $86.9 \%$, specificity $78.6 \%$, PPV 76.9 and NPV 88\%. In a systematic review, the overall pooled sensitivity and specificity from 13 studies of lacunear spaces diagnosing MAP was $77 \%$ and $95 \%$ respectively, with an overall diagnostic accuracy of $88 \%{ }^{(9)}$.

\section{Regarding loss of the retroplacental clear zone :}

This study showed Sensitivity, specificity, PPV, NPV and accuracy were $82.9 \%, 85.7 \%, 96.7 \%$, $50 \%$ and $83.3 \%$ in correlation with histopathological assessment, in addition our study showed Sensitivity, specificity, PPV, NPV and accuracy were $80.6 \%, 87.5 \%, 90.6 \%, 78.6 \%$ and
$85 \%$ in correlation with intra-operative assessment. Wong et al. ${ }^{(10)}$ found absence of the clear space in $37(65 \%)$ women without placenta accreta and in $100 \%$ of those women with it. Hence, it is sensitive but not specific. The primary use of the clear space appears to be that its presence effectively excludes placenta accreta because it has a high negative predictive value (NPV), in contrary, Finberg and Williams ${ }^{(11)}$ stated that the loss of the retroplacental clear zone accounts for the majority of False Positive results and the criterion should not be used by itself to make the diagnosis, and Comstock ${ }^{(\mathbf{1 2})}$ stated that overall sensitivity of $7 \%$ for clear space alone at 15-20 weeks and 7\% from 15-40 weeks. The positive predictive value was $6 \%$.

\section{Regarding interruption of the bladder wall :}

This study showed the Sensitivity, specificity, PPV ,NPV and accuracy were $80 \%, 42.9 \%, 87.5 \%$, $30 \%$ and $73.8 \%$ respectively in correlation with histopathological assessment, in addition our study showed Sensitivity, specificity, PPV, NPV and accuracy were $77.8 \%, 70.8 \%, 80 \%, 72 \%$ and $76.7 \%$ respectively in correlation with intra-operative assessment.

Our study agreed with Cali et al. ${ }^{(7)}$ where this criterion showed sensitivity $70 \%$, specificity $100 \%$, PPV 100\%, NPV 100\%, Unlike Comstock (6), where this finding had Sensitivity $20 \%$, PPV $75 \%$, and Wong et al in 2008 Sensitivity $11 \%$, specificity $100 \%$.

\section{Regarding the presence of placental bulge :}

This study showed Sensitivity, specificity, PPV, NPV and accuracy were $57.1 \%, 42.9 \%, 83.3 \%$, $16.7 \%$ and $54.8 \%$ respectively in correlation with histopathological assessment, in addition our study showed Sensitivity, specificity, PPV, NPV and 
accuracy were $58.3 \%, 62.5 \%, 66.7 \%, 50 \%$ and $58.3 \%$ respectively in correlation with intraoperative assessment.

Our study agreed with Comstock ${ }^{(12)}$ who stated that placental bulge isn't sensitive but didn't agree him in being specific where he found it a specific sign.

Regarding the presence myometrial thinning :

This study showed Sensitivity, specificity, PPV, NPV and accuracy were $74.3 \%, 42.9 \%, 86.7 \%$, $25 \%$ and $69 \%$ respectively in correlation with histopathological assessment, in addition our study showed Sensitivity, specificity, PPV, NPV and accuracy were $75 \%, 66.7 \%, 74.2 \%, 64 \%$ and $70 \%$ respectively in correlation with intra-operative assessment.

Our study didn't agree with Wong et al. ${ }^{(10)}$ who found a sensitivity of $22 \%$, specificity of $100 \%$, PPV of $100 \%$ and NPV of $89 \%$ and Twickler et al. ${ }^{(13)}$ who found a sensitivity $100 \%$, specificity $72 \%$, PPV $72 \%$, and NPV $100 \%$.

$>$ Regarding the uterovesical hypervascualrity using Color Doppler Flow

This study showed Sensitivity, specificity, PPV ,NPV and accuracy were 80\%, 42.9\% , 87.5\%, 30\% and $73.8 \%$ respectively in correlation with histopathological assessment, in addition our study showed Sensitivity, specificity , PPV ,NPV and accuracy were $80.6 \%, 79.2 \%, 82.3 \%, 30 \%$ and $73 \%$ respectively in correlation with intra-operative assessment.

Our study agreed with Cali et $\boldsymbol{a l} .{ }^{(7)}$ where it showed Sensitivity $90 \%$, specificity $100 \%$, PPV $100 \%$, NPV 97\%.

\section{Regarding presence of abnormal bridging vessels} between the placenta and the bladder wall :

This study showed Sensitivity, specificity, PPV, NPV and accuracy were $57.1 \%, 14.3 \%, 76.9 \%$, $6.3 \%$ and $50 \%$ respectively in correlation with histopathological assessment, in addition our study showed Sensitivity, specificity , PPV ,NPV and accuracy were $58.3 \%, 58.3 \%, 64.5 \%, 48.2 \%$ and $56.7 \%$ respectively in correlation with intraoperative assessment.

Our study agreed with Cali et al. ${ }^{(7)}$ where it showed sensitivity 39\%, but didn't agree regarding specificity as it showed specificity $100 \%$, in contrary our study didn't agree with Comstock and Bronsteen ${ }^{(14)}$ who showed that the bridging vessels had sensitivity, specificity, PPV and NPV 89, 96, 80 and $98 \%$, respectively.

$>$ Regarding the presence lacunae feeder vessels : This study showed Sensitivity, specificity, PPV ,NPV and accuracy were $51.4 \%, 42.9 \%, 81.8 \%$,
$15 \%$ and $50 \%$ respectively in correlation with histopathological assessment, in addition our study showed Sensitivity, specificity, PPV ,NPV and accuracy were $52.8 \%, 54.2 \%, 60 \%, 43.3 \%$ and $51.7 \%$ respectively in correlation with intraoperative assessment.

\section{CONCLUSION}

It could be concluded that the accuracy of abnormal placental lacunae, loss of retroplacental clear zone, bladder wall interruption, myometrial thinning and uterovesical hypervascularity are the most important ultrasound criteria in the diagnosis of placenta accreta among the patients who had a previous CS with a placenta previa overlying the previous uterine scar. Loss of retroplacental clear zone and presence of abnormal placental lacunae are the most accurate ultrasound criteria that predict the patients who will mostly have cesarean hysterectomy.

\section{RECOMMENDATIONS}

- Early detection of Cesarean Scar pregnancy 'CSP' as early as 6 weeks of gestation should be encouraged as it has been established that CSP is the main precursor of abnormally invasive placenta and its early detection could offer better chances and allow better maternal counseling.

- Ultrasound has been proved to show reasonable accuracy in diagnosis of placenta accreta among cases of placenta previa with previous CS scar, also to predict the possible co-morbidities.

- This study showed that five ultrasound criteria are the most accurate in the diagnosis of placenta accreta which are loss of retroplacental clear zone, presence of placental abnormal lacunae, bladder wall interruption, myometrial thinning and the presence of uterovesical hypervascularity.

- Also, this study showed that two ultrasound criteria are the most accurate in the prediction of the patients who will mostly have cesarean hysterectomy which are loss of retroplacental clear zone, presence of placental abnormal lacunae.

\section{REFERENCES}

1. Tseng JJ, Chou MM, Hsiehb YT, Wene MC, Hob ES, Hsuf SL (2006): Differential expression of vascular endothelial growth factor, placenta growth factor and their receptors in placentae from pregnancies complicated by placenta accrete. Placenta, 27:70-8.

2. Oyelese KO, Smulian JC (2006): Placenta previa, placenta accreta, and vasa previa, Obstet Gynecol., 107:927-41. 
3. Wu S, Kocherginsky M, Hibbard JU (2005): Abnormal placentation: twenty-year analysis. Am J Obstet Gynecol., 192(5): 1458-1461.

4. Al-Serehi A, Mhoyan A, Brown M, Benirschke K, Hull A, Pretorius DH (2008): Placenta accreta: an association with fibroids and Asherman syndrome. J Ultrasound Med ., 27:1623-8.

5. Shih JC, Palacios Jaraquemada JM, Su YN, Shyu MK, Lin CH, Lin SY, Lee CN (2009): Role of three-dimensional power Doppler in the antenatal diagnosis of placenta accreta: comparison with gray-scale and color Doppler techniques, Ultrasound Obstet Gynecol., 33: 193 203.

6. Comstock $\mathbf{C ( 2 0 1 1 ) : ~ T h e ~ a n t e n a t a l ~ d i a g n o s i s ~ o f ~}$ placental attachment disorders. Curr Opin Obstet Gynecol., 23(2):117-22.

7. Calì G, Giambanco L, Puccio G, Forlani F (2013): Morbidly adherent placenta:Evaluation of ultrasound diagnostic criteria and differentiation of placenta accreta from percreta. Ultrasound Obstet Gynecol., 41:406- 12.

8. Yang JI, Lim YK, Kim HS, Chang KH, Lee JP, Ryu HS (2006): Sonographic findings of placental lacunae and the prediction of adherent placenta in women with placenta previa totalis and prior Cesarean section. Ultrasound Obstet Gynecol., 28(2):178-182.

9. D'Antonio F, Iacovella C, Bhide A (2013): Prenatal identification of invasive placentation using ultrasound: systematic review and metaanalysis. Ultrasound Obstet Gynecol ., 42: 509517.

10. Wong HS, Cheung YK, Williams E (2012): Antenatal ultrasound assessment of placental/myometrial involvement in morbidly adherent placenta. Obstet Gynaecol., 52: 67-72.

11. Finberg HJ, Williams JW (1992): Placenta accreta: prospective sonographic diagnosis in patients with placenta previa and prior cesarean section. J Ultrasound Med., 11:333-43.

12. Comstock C (2005): Antenatal diagnosis of placenta accreta, a review. Ultrasound Obstet Gynecol., 26: 89-96.

13. Twickler DM, Lucas MJ, Balis AB, SantosRamos R, Martin L, Malone S, Rogers B (2000): Color flow mapping for myometrial invasion in women with a prior cesarean delivery. J Matern Fetal Med., 9: 330-335.

14. Comstock CH, Bronsteen RA (2014): The antenatal diagnosis of placenta accrete. BJOG. 121:171-81. 